\title{
Shaping afuture countryside. Light and shadow on rural settlement's models in Chinese urban-rural
} continuum

\begin{abstract}
With the turn of the millennium, Chinese central government issued arrays of policies targeted to promote virtuous cycles of vitalization in rural areas, mitigate the socio-economic gap with urbanised regions, and face the problem of food security. The current transition is leading China to have an ever-saturated land where the boundaries between human settlements are elusive and blurred, shaping what is scholarly labelled as an urban-rural continuum. The settlement's schemes realized over the last years, that consists of small or medium size towns as the result of natural villages relocation or new agglomerations, intercepts the call for urbanity, and its related amenities in terms of infrastructure and services - or, in aword, the desire for ahouse in the city - emerging from the marginalized rural citizens. The authors found that such controversial practices are shaping the new Chinese countryside which, conceived as aform of sustainable development by national programs, turned out to impact significantly on the people lifestyle as well as the built environment. Based on several months on-field observations and recent literature, the paper reveals atwo-fold degree of resilience: weak about the real production of space for dwelling and robust about the intangible culture composed by indigenous beliefs and symbolism entangled with the concepts of home and family
\end{abstract}

Keywords: China, development, rural, countryside, housing

\section{Introducing urbanisation as the principal mean} of economic development

With the promulgation of an arrays measures under the well-known label of Reform and Opening policies, promoted by Deng Xiaoping since the 1980s, China has started ashocking socio-economic transition to achieve the status of developed and modern country. The results of the path taken four decades ago are under the lights of media, which paint the Chinese megacities as the tangible effects of this process. This article moves from two assumptions. First, the Chinese transition is just halfway and it is expected to last for several decades. This raises many concerns about how sustainability will be applied to such afast development model (Tilt 2010) and challenges the canonic notion of city (Meriggi 2018). Second, urbanisation is not the result of the transition. Conversely, it is the principal and controversial mean. The Chinese model for mass housing is the result of precise land optimization through engineering-based approaches, based on the maximization and velocity of profits (Sudjic 2005: 2; Chow 2015: 74; Fabris and Semprebon 2019: 104-113). Against the backdrop of the theories of "ecological civilization", urbanisation is accepted as apositive value (Bai et al. 2011). More, we witness an unquestioned faith in it, perhaps son of apositivistic approach toward development, that turns urbanisation into the unavoidable form of national growth. The Chinese model applied to ordinary practices is commonly acknowledged by scholars to produce built forms insensible to contextual specificities, adopting repeated solutions flattened by the absence of typological variations (Huang 2006) (Figure 1, 2, 3, 4, 5). The thrusts of urban growth can be found in several factors. One is the institution of the so-called "Special Economic Development Zones" (SEZs), namely areas which benefit from legal, fiscal and use privileges to facilitate land development and foreign investments, among which Shanghai and Shenzen are the most known expressions. Another element is the trading of land use rights, which produces funds to be devoted to construction activity such as infrastructures. In China all the land is astateowned property but the right of using it can be sold for certain time-spans. Moreover, the relaxation of the rigid household registration system, the hukou, exacerbates the already consistent migration flow from ruralities to urban agglomerates (Friedman 2005; Zhu 2017: 3;). ${ }^{1}$

\section{Rural Urbanisation: from aspontaneous process to apolitical goal}

In parallel with urban expansion, another form of urbanisation is the re-shaping of the Chinese territories, the one known as in-situ urbanisation. This consists of the production of urban-like environments in rural areas, that in China comprehend all those territories under the jurisdiction of villages and townships. The 


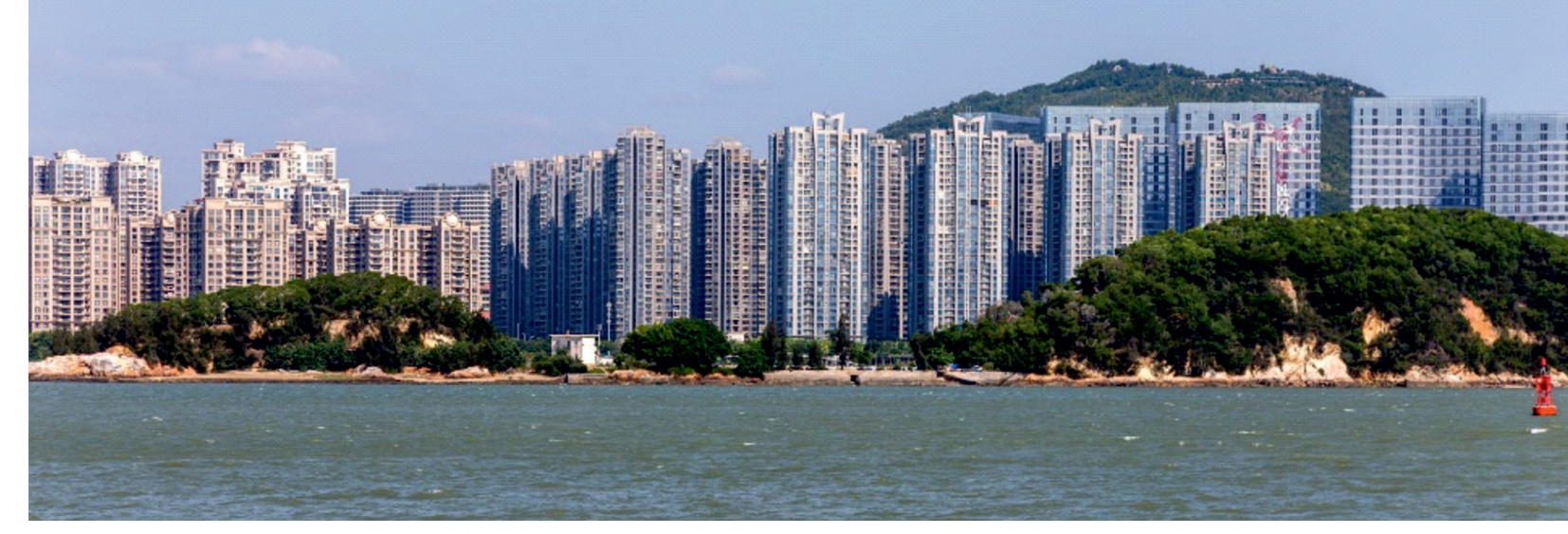

III. 1. Xiamen 2018 (Fujian Province). Picture by the first author

countryside is experiencing aprofound transition as well, whose turning points are the proclamation of the People Republic of China, which imposed anew social order on the long-lasting traditional one, and the new era inaugurated with the Reform and Opening policies issued since the 1980s. In particular, the implementation of the Household Responsibility system, which ensured farmers direct access to the markets' opening, represented acatalyst for socioeconomic and cultural development. Peasants' revenue was put in housing construction, either replacing existing dwellings or adding new volumes on the arable soil. The introduction of modern techniques, especially reinforced concrete, monsured famers to build taller and larger houses, able to host all the members of the tivals. The model of rural dwelling shifted from the traditional one-storey courtyard (or semi-courtyard) complex to the free-standing multistoreys box-alike "villa" (Knapp 2005: 6), arough concrete structure to dress with afancy apparatus of decorations inspired both to local and western elements (Figure 6). This happened in aspontaneous and pervasive way in close relation with processes of rural exodus abandonment of existing buildings, residential land "villas 17. Sun et al. 2011:355). At the turn of the millennium Professor Wen Tiejun formulated the "three rural issues"2, framing the contempory rural issues" , framing the contemporary challenges of rural development (Wen 2007: 24; Pan, Luo et coupled with the problem of "food security" (Brown coupled with the problem of "food security "(Brown

many concerns among Beijing's policy-makers about how to deal with the countryside restructesired development. Moreover, land reclamation is apressing topic in national agenda considering the relationship between arable land and population in China. Indeed, only $10 \%$ out of the Chinese territory is arable, considerably lower than the world amount counting for $24 \%$. Meadows and forests are appreciably inferior too (Zan et al. 2018). An array of top-down policies have been defined at different levels of administration, including the 2006 "Building anew socialist countryside "(Long, Lu, Li et al. 2010: 466; Ahlers and Schubert 2009: 36), the 2013 "Beautiful Village" (Zhang 2018 13; Li 2016: 72), and the 2018 "Strategic plan for Rural Revitalization 2018-2022," in order to stimulate virtuous practices of rural development. A new interest towards the restructuring of the countryside is also witnessed by cultura Institutions, such athe Chinese participation to

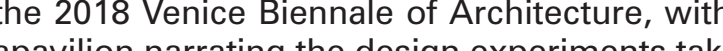
apavilion narrating the design experiments tak"Building intemer 2018). The current transition of ruralities has been acknowledged to be apotential asset for creating space for new types of living and producing more sensible to the ecological agenda and, at the same time, able to meet the aspirations of rural citizens. Thus, the governments assumed acrucial position within the decisionmaking process, either appointing private and

III. 2. Shanghai 2018. Picture by the first author
III. 3. Xi'an 2018 (Shaanxi Province). Picture by the first author

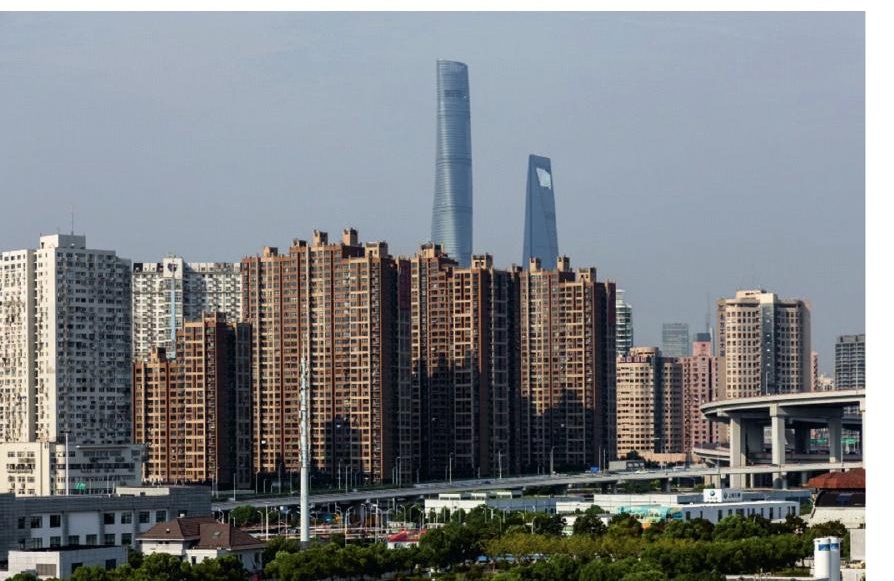

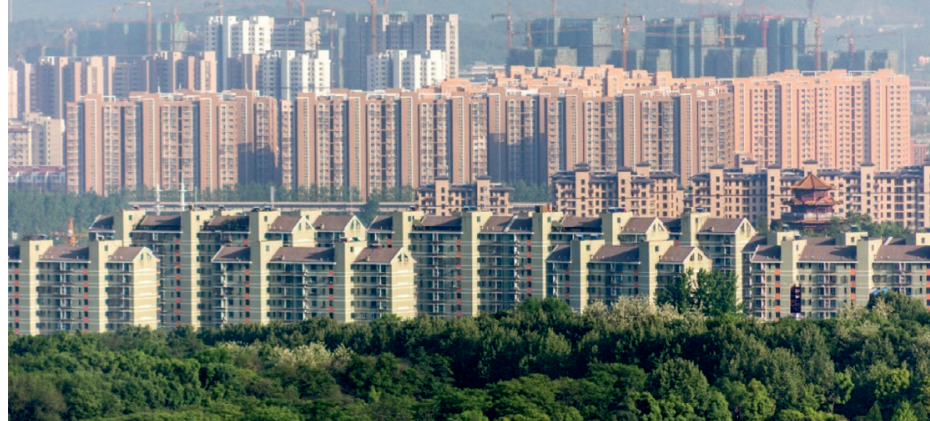

III. 4. Nanjing 2018 (Jiangsu Province). Picture by the first author
III. 5. Hangzhou 2018 (Zhejiang Province). Picture by the first author

public design institutes to propose pilot projects or providing fundings for bottom-up applications by local authorities. The main goal, at the present stage, tion projects to cover the largest spectrum of possible strategies of rural revitalization, from of poslearn and be inspired. The campaign is seeking the improvement of the rural cenvironment mainly the moting urban living standard in the countryside, pecially through the beautification of public spaces, the strengthening of sanitary infrastructures, the reorganisation of settlement's schemes and the supply of services to support entrepreneurial innovation.

\section{Discussing on arecent case of rural restructuring}

During arecent visit, the authors had the chance to visit "Jiankou 'Happy Communities' of the new countryside" anew rural settlement in Fujian Province (Figure 7, Fig ure 8 , Figure 9). A brief description of the project is reported on some illustrative panels in the public hall, reciting:

Jiankou Village is located by the Laibang Highway (County Road No. 241), with an area of 3,5 sq km and apopulation of 2.685 inhabitants. It was once alittle-known remote village. Since it was included into the pilot projeth for the "Happy Communities in 2012, the community started from "dismantling the old village and building the new one, and worked to transform the settlemen in a"happy dwelling place in amountainous area, with an agricultural park and central village" that combines $\mathrm{li}$ vable environment, ecological agriculture and farmland sightseeing. By far, the village has reclaimed $81.332 \mathrm{sq}$ $\mathrm{m}$ of arable land, built 283,5 -storey townhouses for 194 houscholds, and realized intrastructures like the waste collection stations, the sewage treatment facilites, afte centres and lisure squar. Jianko creaty an Agricultural Product E-Commerce Mall to trade its distinctive agricultural products integrating the flower industry and the agricultural products processing with onlin retail and logistics. The new settlement is characterized by "crystal clear streams with reflections of beautifu flowers and fragrant fruits surrounded by thinly-built fences," but also enhances the integration between industries and villages, mobilizing rural resources, and helping farmers to get rich."

From one side, the project optimizes the spatial layout providing the largest amount of services at the lowest price.
The Village can praises different achievements like the consolication of more than $80.000 \mathrm{sq} m$ of arable land, the supply to 194 households of new dwellings, ion of infrastrutura networs and the intoduction of new sources of economy. It reduces the disparities between the rural and the urban, introducing asmal lown atmoshere given by the new compact fabric. On the other side, the realization of the new community required the demolition of the former settlemment according to a "tabula rasa" approach. An urban like model of residence has been imposed through the introduction of anew, anonymous, and insensible grid which organizes the layout. The built form is given by repeated arrays of middle-rise row houses equipped with little gardens in front of the main dwelling's entrance. The typology as well the style is repeated everywhere, without elements of discontinuity, resulting in arigid, monotonous and redundant built form. This solution reveals aprofound indifference to the context both in the built form, whose traces were cancelled, and in the natural environment, since the new planning design could be placed everywhere. There is $n$ clue of cultural inhertance, such as the balanced relation between void and solid spaces, typical of Chinese houses, or the delicate transition between the public street and the heart of the house, historically realized through sequences of yards and articulated pave ments. The result is the loss of both the intangible heritage and the bonds linking the space of living, namely the house, and the space of producing, namely the agricultural crops. The dissolution of the connection between the sell. The dis and its territory, the mankind and the land has been evident to our eyes. Looking

III. 6. A recently built house in avillage on Fujian Province. Example
of box-a-like "villa." Source: picture by the first author (July 2017)

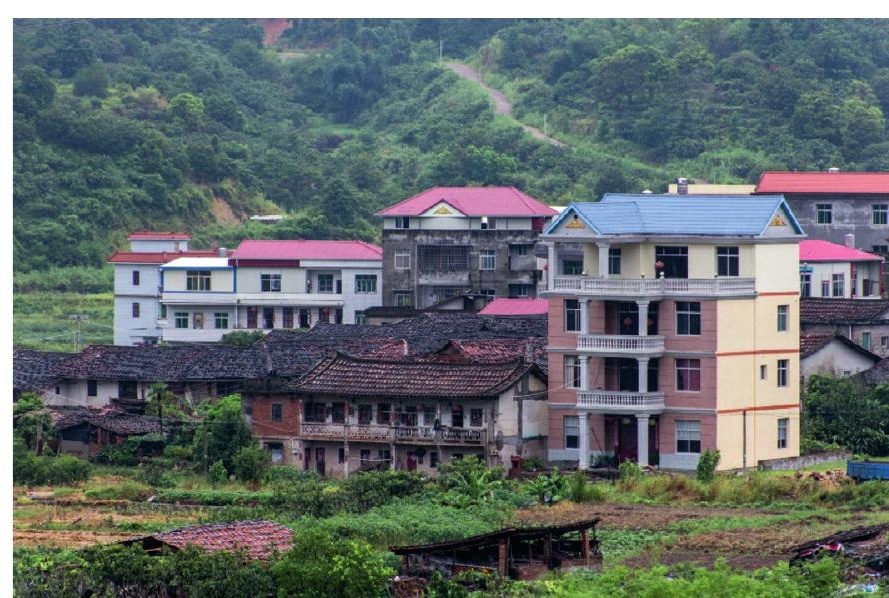




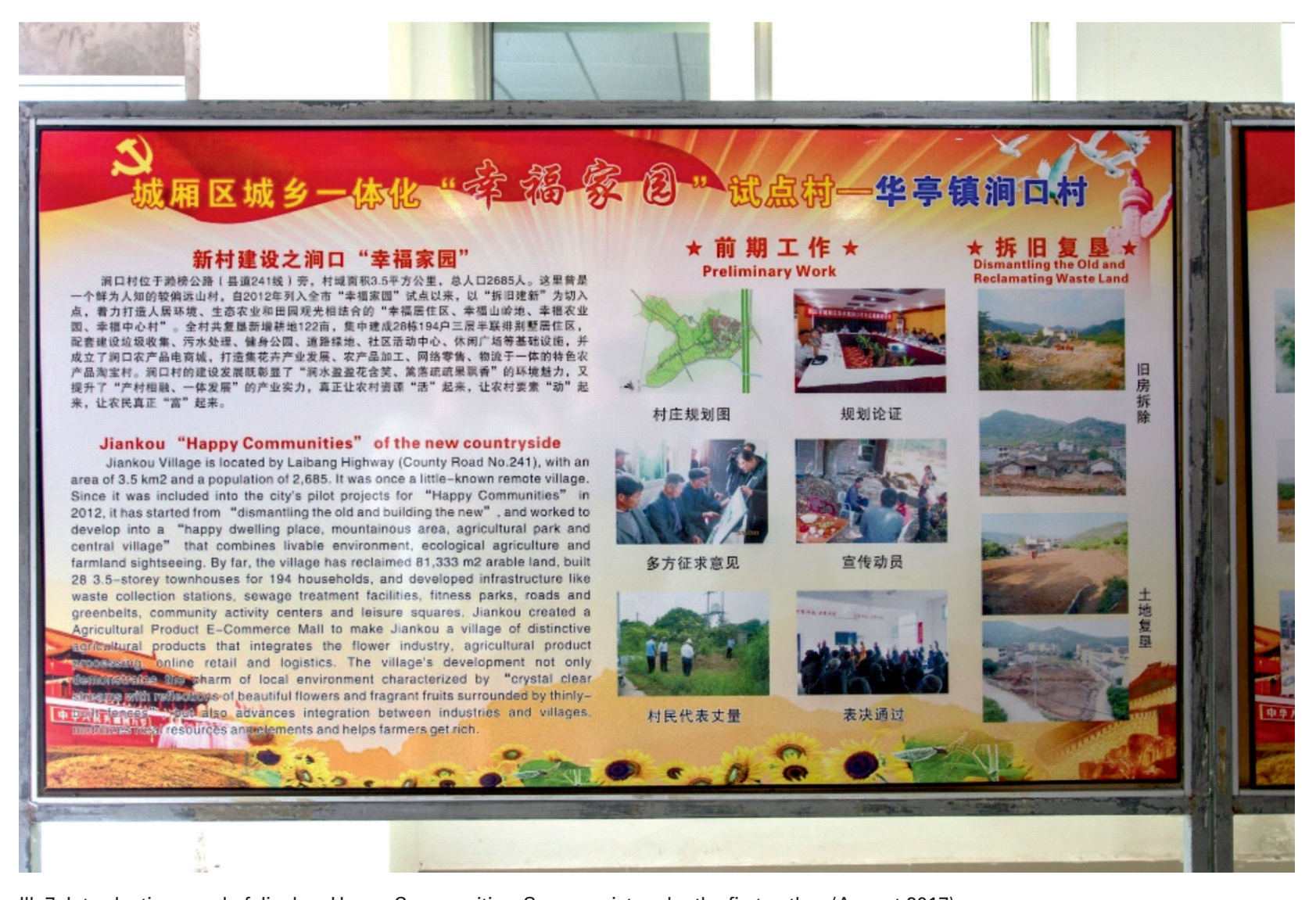

III. 7. Introductive panel of Jiankou Happy Communities. Source: picture by the first author (August 2017)

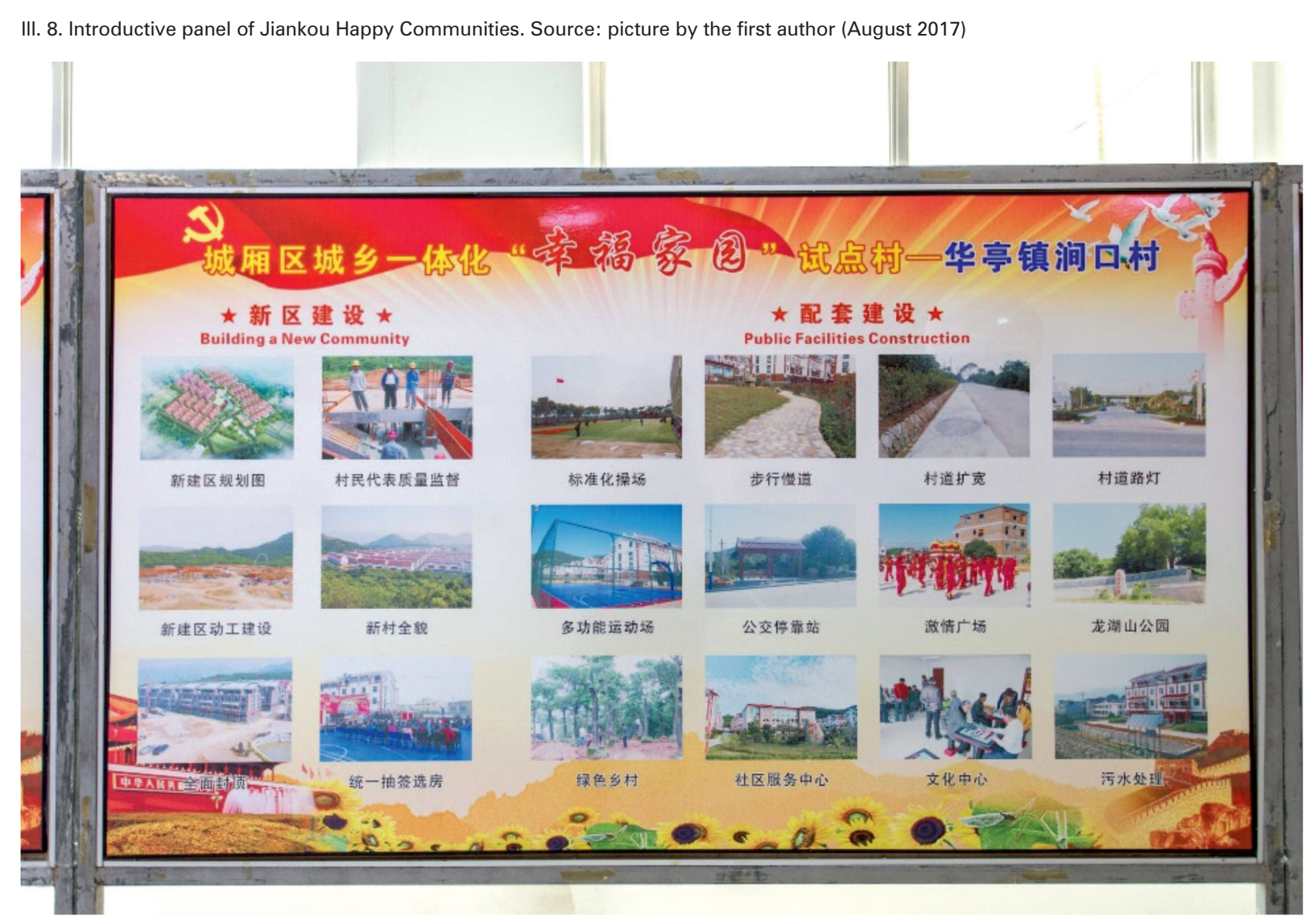

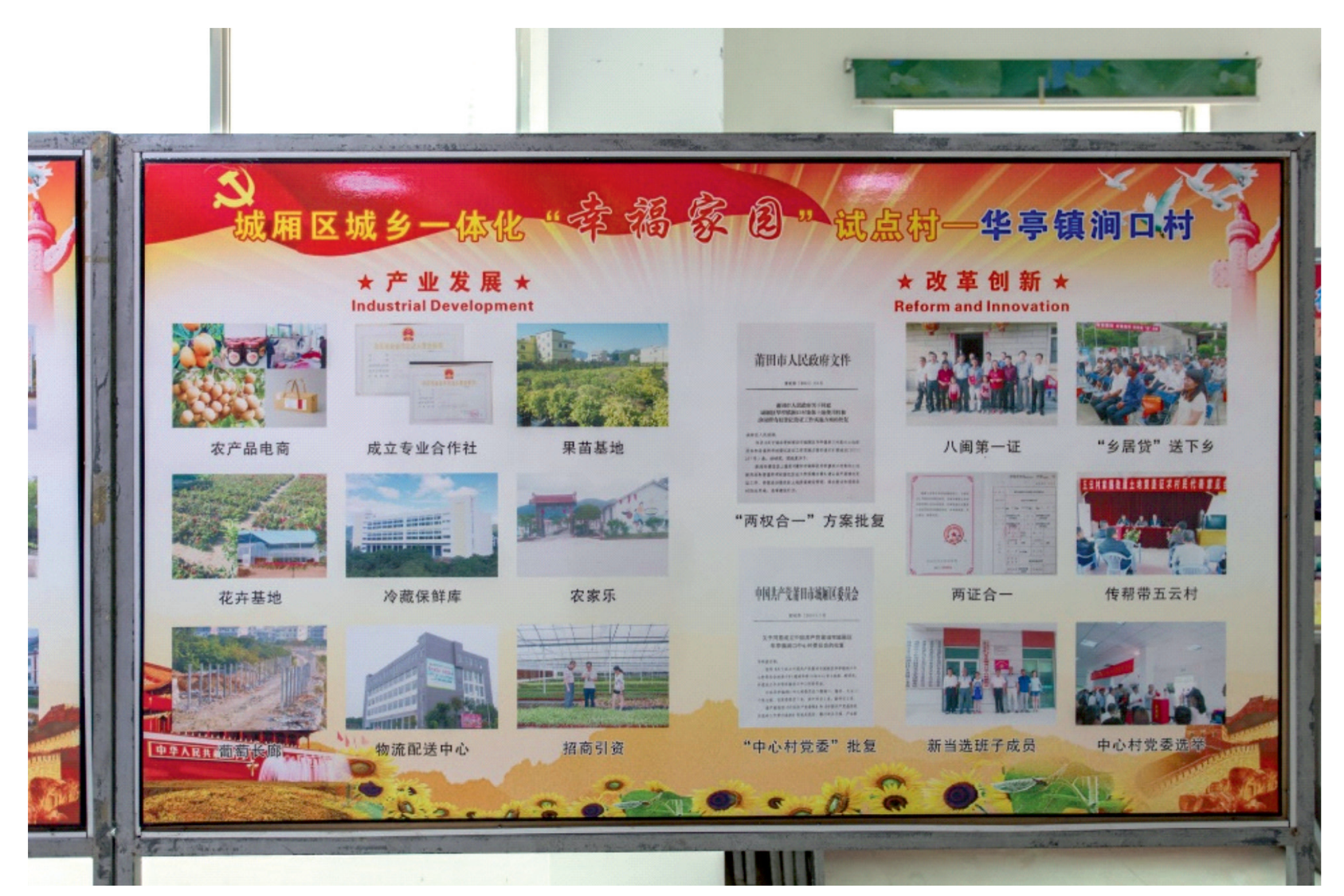

III. 9. Introductive panel of Jiankou Happy Communities. Source: picture by the first author (August 2017)

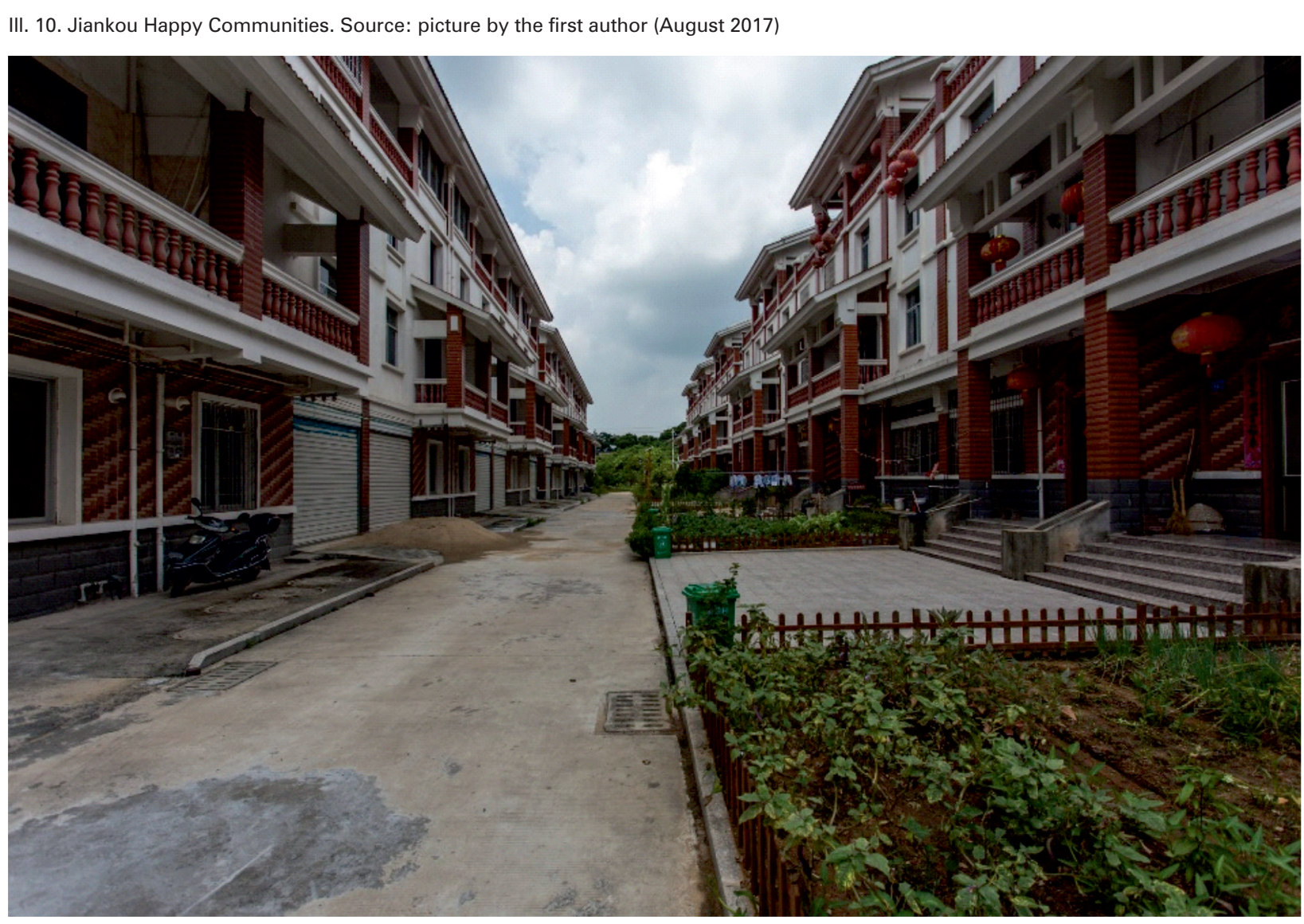




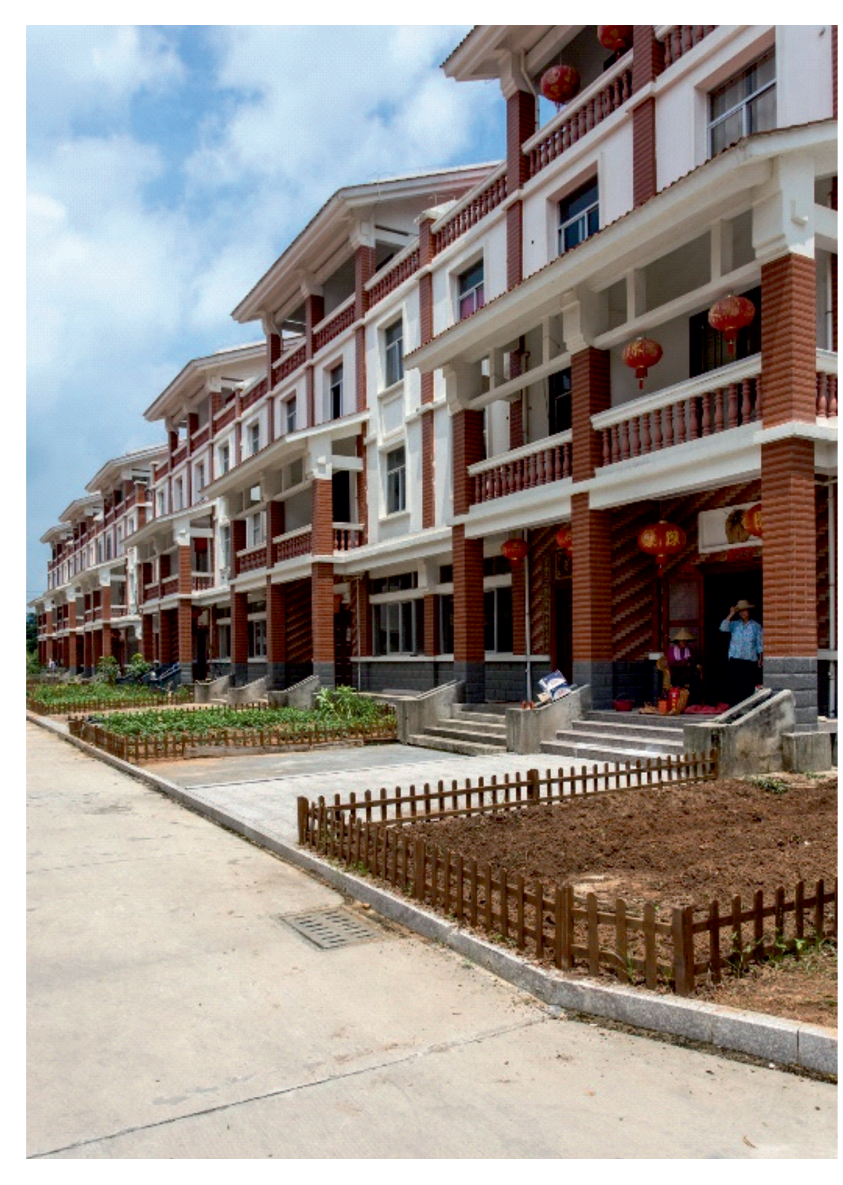

III. 11. Jiankou Happy Communities. Source: picture by the first author
(August 2017)

III. 12. Jiankuo Happy Communities. Source: picture by the first author
(August 2017)

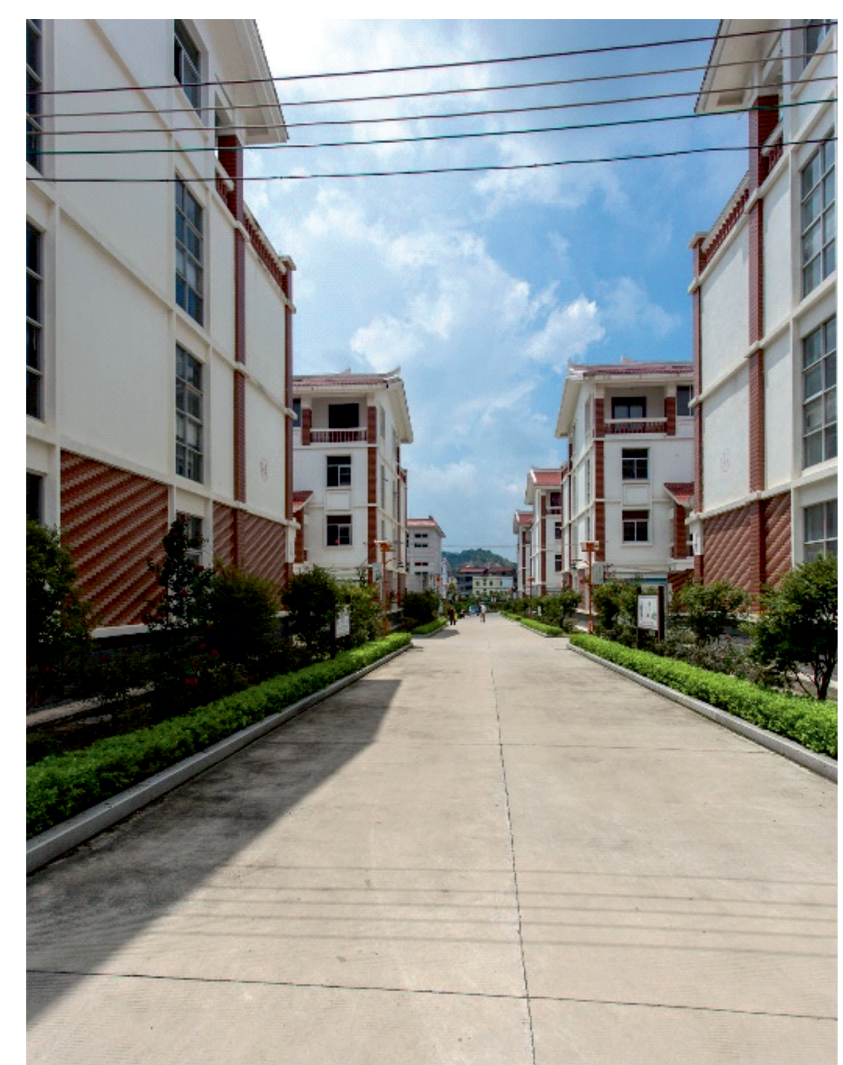

in this project are poor and denote ascarce devotion to the improvement of the selliement's spatial quality. Even though the project aims, and achievements, to concentrate the residental area, the built shaping resonates as an urban peripheral expansion. This pattern negates both the presence of acentre and the consolidated relationships between territory and human activity, afeature that characterized the ruralities over centuries. This settlement's model of integrating the grassroots aspirations, the top-down policies and the natural resources fails with the application of banal solutions in terms of built forms (Figure 10, Figure 11, Figure 12).

Searching new settlement's models starting from strategic approaches

The settlement's schemes realized over the las Thears consisting of small or medium size towns as the result of natural villages relocation or new agglomerations, intercept the call for urbanity, and its related amenities in terms of infrastructure and services - or, in aword, the desire for ahouse in the city - emerging from the marginalized rural citizens. The implementation of the above-mentioned policies resultes in controversial practices such as villages relocations and construction of suburbialike settlements. During our fieldwork, we observed atwo-fold degree of resilience: weak about the real production of space for dwelling, as the case of Jiankuo Village clearly reveals, and robust about the intangible culture composed by indigenous beliefs and symbolism entangled with the concepts of home and family. This materializes in concomitance with the strong presence of religious and sacred spaces, such as temples and family shrines, and in the dwellings interiors, manifesting in domestic furniture and wall's decorations. Even though such acontrasting atmosphere, between inside and outside, sacred and secular may puzzle external observers, we have found that this apparent ambiguity is strongly radicated in the Chinese cultural background (Knapp 2005). We argue that the recent arfor of policies and initiatives opens ahuge space for design experimentalions. Some archilectura practices have engaged this new challenge, as in (Bolchover and in 2014; Vall 2016). However, we found aconsistent gap between the proclaimed purposes and guidelines and the ordinary practices. In order to mitigate the loss of cultural diversities, the authors suggest that asmart strategy should start by considering what exists as apotential asset, available for practices of re-cycling such as the gradual demolition of dilapidated artefacts, the introduction of temporary uses, or the punctual action on the buildings in acceptable state of conservation. The case study illustrated suggests that land use optimization enhances the services' quality but a the same time, threatens the aesthetic and cultural values that permeate the rural settlements. In our opinion, in Jiankou Village this happened because the planning design for the new community missed the which rion of architectural and urban design disciplines, "hich resigned in front of comforting methodologies of rather than qualitative discernment and critic thinking.

ENDNOTES

The hukou system is used by the government to plan expenses for so-
cial services. According to the hukou, the population is divided into two categories: rural and urban. This generates two classes that are hardly possible to switch.

reral society and rural agriculture.

J Tankou Happy Communities Village, Putian City District, Fujian Province,
T.ext taken from the Jiankou Village illustrative panel illustrated in picture

BIBLIOGRAPHY

11) Ahlers Anna L.., Schubert Gunter."Building a New Socialist Country-
side" - Only a Political Slogan? In Journal of Current Chinese Affairs 38

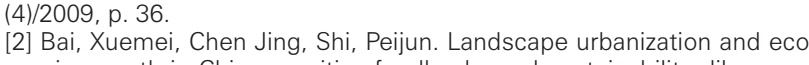
nomic growth in China: positive feedbacks and sustainability dilemmas in Environmental science \& technology iss. $46 / 2011$, p. 136 .
3] Bolchover, Joshua and Lin John. Rural urban framework. Birkhäuser, [3] Bolchover
Basel 2014

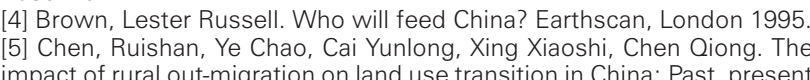

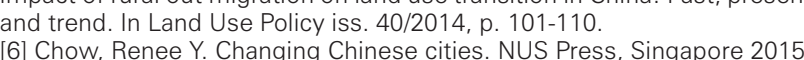
[6] 74

P. 74 .
[7 Fabris, Luca Maria Francesco and Semprebon Gerardo. The chinese
'high and slender' condominium. In Techne - Journal of Technology for "high and sulender' condominium. In Techne - Journal of Technology for
Architecture and Environment, 17/2019, p. 104-113. Architecture and
[8] Firiedmann, Jo/
Minneapolis 2005 .
G

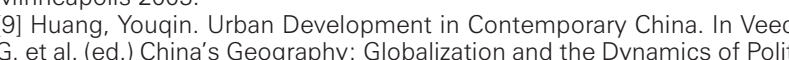
cal, Economic and Social Change. Roman \& Littlefield Publishers, Boulder 2006, p. $233-262$.
101

House, home family China's Houses, Homes, and Families. Chap. 1 Knapp and Kai-yin Lo. University of Hawali'i Press, Honolulu 2005 . C1] Li Xiangning (edit byl). Building a Future Countryside. Catalogue of the
[12] LiZhongxin. Research on Beautiful Countryside Construction
in China: Taking Shandong Province as an Example. In Canadian Social Studies 12 (12)/2016, p. 72. 13] Liu, Yansui, Yu Liu, Yangfen Chen and Hualou Long. The pro-
cess and driving forces of fural hollowing in China under rapid ur

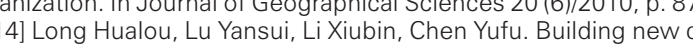
intryside in China: A geographical perspective. In Land Use Polic
272010 , p. 458. $15 \mathrm{~L}$ Lo, $\mathrm{p}$, Hualou, Li Yurui, Liu Yansui, Woods Michael, Zou Jian,
Accelerated restructuring in rural China fueled by 'increasing vs.

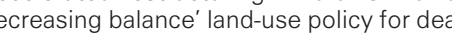
16. Meriggi, Maurizioi Larchitettura del continuo urbano-rurale in
Cina. Insediamenti Hakka nel Guangdong Orientale. ArabAFenice. Torino 2018.

17] Pan Jiaen, Luo Chia-Ling, Wen Tiejun. 'Three "centuries': the context and development of rural construction in China. In Inter18 Roy, Ananya, Ong, Aihwa led.). Worlding Cities. Asian exper-
ments and the art of being global, Wiley-Blackwell, Chichester 19] Sudjic, Dejan. The speed and the friction. In Burdett R. (Ed.) Shanghai: the fastest city? Urban Age 2005, p. 2 . (Hollow villages and rural restructuring in major rural regions of China: A case study of Yu-
cheng City, Shandong Province.In Chinese Geographical Science $21(3) / 2011$, p. 355

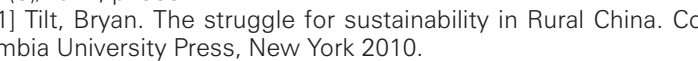
22] Valle, Pietro. Ress, New York 2010.

. Deconstructing modernization. In Chinese Socio24] Whyte, Martin K. One country, two so societies. Rural-urban ine
[2 dge MA 2010

125] Williams, Austin. China's Urban Revolution. Understanding
Chinese Eco-Cities, Bloomsbury Publishing, London and New Yo 26] Zan Luca, Yu Bing, Yu Jianli, Yan Haiming. Heritage Sites in [27] Zhang, Xiaochun (edit by). Beautiful Villages. Rural Construges Publishing, Victoria 2018, p. 14. 14 . [28] Zhu, Xinhua. Impact of the Household Registration System on
Farmers'. 